\title{
Docência da educação profissional: entre a universalidade e a singularidade
}

\author{
Professional education teaching: between \\ universality and singularity
}

La enseñanza en la educación profesional: entre la universalidad y la singularidad

Marilandi Maria Mascarello Vieira (DDa

Maria CRIstina Pansera de Araújo (iDb

Josimar de APARECIDo VIEIRA (Didc

\section{Resumo}

Este trabalho tem como objetivo identificar como os professores da educação profissional efetivam a sua docência enfocando os conhecimentos considerados relevantes e os saberes requeridos para o exercício da docência de modo semelhante aos demais níveis e etapas da educação e as especificidades da educação profissional. Toma como referência, em relação aos saberes docentes, os estudos de Imbernón, Nóvoa, Shulman e Tardif e autores brasileiros que discutem a temática. A abordagem metodológica foi orientada pela pesquisa qualitativa, do tipo pesquisa de campo e os dados empíricos foram produzidos por meio de estudo de caso instrumental com uso de entrevista realizada com dez professores que atuam nos cursos técnicos de nível médio em um Instituto Federal de Educação, Ciência e Tecnologia situado no sul do Brasil. Os resultados indicam que, de modo geral, os professores precisam construir saberes que envolvem a docência de modo

\footnotetext{
a Universidade Comunitária da Região de Chapecó (Unochapecó), Chapecó, SC, Brasil. Doutora em Educação nas Ciências, e-mail: mariland@unochapeco.edu.br

b Universidade Regional do Noroeste do Estado do Rio Grande do Sul (UNIJUÍ), ljuí, RS, Brasil. Doutora em Genética e Biologia Molecular, e-mail: pansera@unijui.edu.br

' Instituto Federal de Educação, Ciência e Tecnologia do Rio Grande do Sul - Câmpus Sertão, Sertão, RS, Brasil. Doutor em Educação, e-mail: josimar.vieira@sertao.ifrs.edu.br
} 
universal, acrescido de singularidades que distinguem a educação profissional dos demais níveis e etapas da educação.

Palavras-chave: Educação Profissional. Formação de professores. Saberes docentes.

\begin{abstract}
This work aims to identify how teachers of professional education carry out their teaching, focusing on the knowledge considered relevant and the knowledge required for the exercise of teaching in a similar way to other levels and stages of education and the specificities of professional education. In relation to teaching knowledge, the studies by Imbernón, Nóvoa, Shulman and Tardif and Brazilian authors who discuss the theme. The methodological approach was guided by qualitative research, of the field research type, and the empirical data were produced by means of a case study using interviews with ten teachers who work in high school technical courses in a Federal Institute of Education, Science and Technology located in southern Brazil. The results indicate that, in general, teachers need to build knowledge that involves teaching in a universal way, plus singularities that distinguish professional education from other levels and stages of education.
\end{abstract}

Keywords: Professional education. Teacher education. Teachers' knowledge.

\title{
Resumen
}

Este trabajo pretende identificar la forma en que los profesores de formación profesional llevan a cabo su enseñanza, centrándose en los conocimientos que se consideran relevantes y en los que se requieren para el ejercicio de la docencia de forma similar a otros niveles y etapas educativas y en las especificidades de la formación profesional. Toma como referencia, en relación con el conocimiento de los profesores, los estudios de Imbernón, Nóvoa, Shulman y Tardify autores brasileños que discuten el tema. El enfoque metodológico se orientó por la investigación cualitativa, del tipo investigación de campo y los datos empíricos se produjeron por medio de un estudio de caso con el uso de una entrevista realizada a diez profesores que trabajan en cursos técnicos de nivel secundario en un Instituto Federal de Educación, Ciencia y Tecnología ubicado en el sur de Brasil. Los resultados indican que, en general, los profesores necesitan construir un conocimiento que implique enseñar de forma universal, además de las singularidades que distinguen a la formación profesional de otros niveles y etapas educativas.

Palabras clave: Formación profesional. Formación de profesores. conocimientos de los profesores. 


\section{Introdução}

O mundo do trabalho e, de modo particular, as suas formas de organização vêm se modificando nas últimas décadas em decorrência das mudanças sociais, econômicas e culturais que caracterizam a sociedade digital. Kanan e Arruda (2013, p. 584) apontam como características do trabalho na atualidade "[...] a realocação da força de trabalho da indústria para os serviços, do trabalho assalariado para o autônomo, do emprego presencial para o virtual". Também há mudanças nos processos de produção e de prestação de serviços, o que exige trabalhadores mais qualificados.

A educação profissional (EP) é impactada pelas exigências desses novos tempos e torna-se cada vez mais requerida pelos trabalhadores que, por meio dela, buscam qualificar-se para se manterem ou ingressarem no mundo do trabalho, o que resulta na ampliação da demanda por vagas nas instituições que oferecem essa modalidade de ensino. Assim, a expansão da EP está prevista nas metas 10 e 11 do Plano Nacional de Educação (2014-2024).

A meta 10 pretende "oferecer, no mínimo, 25\% (vinte e cinco por cento) das matrículas de educação de jovens e adultos, nos ensinos fundamental e médio, na forma integrada à educação profissional" (BRASIL, 2014), como forma de universalizar a educação básica e integrar os jovens e adultos no mundo do trabalho.

O Relatório do $3^{\circ}$ Ciclo de Monitoramento das metas do Plano Nacional de Educação (BRASIL, 2020a, p. 236), apresenta dados de 2015 a 2019 que indicam que essa meta ainda está distante de ser atingida até 2024:

Nos dois primeiros anos da série, o indicador registrou a marca de 2,8\% e, em 2015, atingiu o seu maior patamar (3,0\%). Em 2016, ocorreu um decréscimo de 0,2 pontos percentuais (p.p.), resultando em 2,8\%; em seguida, uma queda significativa de 1,3 p.p., em 2017 (1,5\%); e menos 0,2 p.p. em 2018 (1,3\%). Os resultados de 2019 demonstram um pequeno crescimento do percentual de matrículas da educação de jovens e adultos ofertada de forma integrada à educação profissional de 0,3 p.p., mas ainda distante do estabelecido pela Meta 10 para 2024. 
A meta 11, por sua vez, registra o propósito de "triplicar as matrículas da educação profissional técnica de nível médio, assegurando a qualidade da oferta e pelo menos 50\% (cinquenta por cento) da expansão no segmento público" (BRASIL, 2014). Quanto ao primeiro indicador, tomando como base o número de matrículas de 2013 (1.602.946) a meta é atingir 4.808.838 matrículas em 2024. Dados do referido relatório (BRASIL, 2020a, p. 242), indicam que, em 2019, o número chegou a 1.874.974, o que indica crescimento em torno de 17,0\% no período.

O indicador obteve os maiores valores da série histórica em 2014 (1.886.167), quando cresceu 17,7\% em relação ao ano anterior; depois, sofreu um recuo, em 2015 $(-3,2 \%)$ e em 2016 (-2,7\%). Em 2017, iniciou uma leve recuperação $(0,9 \%)$, que se intensificou em 2018 (4,3\%), permanecendo praticamente estável em 2019 (0,3\%), alcançando 1.874.974 matrículas (BRASIL, 2020a, p. 242).

Assim, os dados indicam que, embora tenha havido ampliação das matrículas, está muito abaixo do esperado e será preciso criar, até 2024, 2.933 .864 novas vagas.

Quanto ao segundo indicador, ou seja, a participação do setor público na ampliação das matrículas, os dados do relatório atestam que

Da expansão total de 272.029 matrículas, 206.037 estão no segmento público, o que representa $75,7 \%$ da expansão observada e a superação do percentual de $50 \%$ de participação prevista no PNE. Contudo, em 2019, a educação profissional técnica de nível médio interrompeu sua sequência de alta no setor público, apresentando retração de 9.913 matrículas. A expansão das matrículas exclusivamente no segmento público atingiu 22,9\%, em 2019 (BRASIL, 2020a, p. 257).

Com relação à formação de professores, a meta 15 do PNE prevê que 100\% dos docentes da educação básica tenham formação de nível superior em cursos de licenciatura na área de atuação. O relatório do $3^{\circ}$ Ciclo de Monitoramento das Metas do Plano Nacional de Educação (BRASIL, 2020a) indica que 63,3\% dos professores que atuam no ensino médio têm formação compatível, porém não apresenta dados relativos à EP. Entretanto, os dados da Sinopse Estatística da Educação Básica do INEP (BRASIL, 2020b), indicam que há em atuação na EP regular 128.535 professores, dos quais 89 têm formação no ensino fundamental, 5.958 têm ensino médio e 122.488 têm formação em nível superior e, dentre esses, 70.135 em cursos de licenciatura e 43.353 não licenciados. Para alcançar a meta do PNE (2014-2014) 
será necessário que 38,5\% deles busquem a formação adequada, já que os licenciados somam $61,5 \%$.

Para suprir essa lacuna histórica na formação dos professores da EP a legislação brasileira tem criado diversas alternativas e, dentre essas, impende mencionar o "notório saber" criado pela reforma do ensino médio, instituída por meio da Lei no 13.415, de 16 de fevereiro de 2017, que incluiu no art. 61 da LDB o inciso IV que considera profissionais da educação os

IV - profissionais com notório saber reconhecido pelos respectivos sistemas de ensino, para ministrar conteúdos de áreas afins à sua formação ou experiência profissional, atestados por titulação específica ou prática de ensino em unidades educacionais da rede pública ou privada ou das corporações privadas em que tenham atuado, exclusivamente para atender ao inciso V do caput do art. 36 (BRASIL, 2017).

O inciso IV flexibiliza a exigência de formação de nível superior para atuação na EP, visto que somente menciona "formação" na área de atuação que será atestada "por titulação específica”, o que não exige certificação de nível superior e muito menos licenciatura. A concepção presente na referida lei é a de que a docência na EP requer domínio de conteúdo, porém dispensa a formação pedagógica.

Nesse sentido, convém refletir sobre o que afirmam Oliveira e Nogueira (2016, p. 150) que, mesmo não se referindo ao notório saber, abordam a problemática:

Registre-se que se reconhece o caráter diferenciado da docência na EP. A diferença em questão tem a ver com a importância de experiência prática na área em que se leciona. Contudo, isso não prescinde da análise crítica do contexto do mercado de trabalho na área, não justificando, mas até reforçando a necessidade da formação acadêmica. A experiência prática na área em que se leciona não substitui nem mesmo uma formação acadêmica aligeirada na área da Forprofep. Em síntese uma Forprofep de qualidade social não prescinde da formação ampla e intensa na área educacional.

As Diretrizes Curriculares Nacionais para a Educação Profissional e Tecnológica, aprovadas pela Resolução CNE/CP no 1, de 5 de janeiro de 2021, determina no art. 53 que a formação inicial dos professores da Educação Profissional Técnica de Nível Médio realiza-se em cursos de graduação, em programas de licenciatura ou outras formas e, no art. 57, menciona os saberes requeridos na atuação desse profissional: 
Art. 57 A formação do docente da Educação Profissional e Tecnológica, além do bom domínio dos saberes pedagógicos necessários para conduzir o processo de aprendizagem de estudantes, requer o desenvolvimento de saberes e competências profissionais, associados ao adequado domínio dos diferentes saberes disciplinares referentes ao campo específico de sua área (BRASIL, 2021, grifos nossos).

Referida legislação faz menção aos saberes necessários à ação docente, tema sobre o qual tem crescido o interesse de pesquisadores, especialmente em pesquisas desenvolvidas nos Programas de Pós-Graduação no Brasil, como atesta o trabalho de Vieira, Vieira e Araújo (2018), que apontou que, dentre 56 trabalhos analisados sobre o tema formação de professores produzidos no período de 2010 a 2107, 26 (46,5\%) abordaram os saberes docentes na EP.

Assim, neste trabalho procuramos evidenciar como os professores que atuam na EP exercem a docência, enfocando os conhecimentos e saberes que constituem, em tese, todos os profissionais em exercício - o que denominamos universais - e o que os particulariza, ou seja, que aspectos da docência são singulares a essa modalidade de ensino.

Metodologicamente o estudo classifica-se como pesquisa qualitativa, de campo, do tipo estudo de caso instrumental realizado num Instituto Federal de Educação, Ciência e Tecnologia localizado na região sul do país. Os instrumentos utilizados foram a entrevista semiestruturada, observação das aulas ministradas por dez professores que atuam em três cursos técnicos de nível médio durante encontros semanais de duas horas, totalizando 74 horas e análise documental (planos de ensino e material didático utilizado). Para esse artigo, entretanto, foi realizado um recorte da pesquisa, explicitando os discursos coletados na entrevista que expressam suas compreensões acerca da atividade docente. Ressalte-se que, dada a impossibilidade de apresentar todas as respostas dos entrevistados, transcrevemos alguns depoimentos em cada categoria a título de mera exemplificação.

O projeto atende aos preceitos éticos da pesquisa, tendo sido aprovado por Comitê de Ética em Pesquisa com Seres Humanos e para preservar a identidade dos participantes neste trabalho usamos nomes fictícios. 
Assim, o presente artigo está organizado em três seções, sendo que na primeira apresentamos o que caracteriza a docência em seus aspectos gerais (universais) e na segunda seção constam os depoimentos relativos às especificidades da docência na EP. Por fim, apresentamos algumas sínteses conclusivas.

\section{Conhecimentos requeridos na atividade docente: aspectos gerais}

Segundo Imbernón (2001), tem sido cada vez mais frequente o acesso dos cidadãos aos sistemas educativos e neles constroem uma visão sobre a profissão docente, incorporando estereótipos, esquemas, imagens e estigmas que não são facilmente superados. A partir desses "modelos", os que ingressam na profissão docente constroem suas referências sobre o que constitui o conhecimento do professor, quer atuem nos componentes curriculares do núcleo comum, quer na formação técnica.

Para identificar os conhecimentos que consideram relevantes para o ensino, indagamos os entrevistados sobre as características reveladoras de um professor referencial, pois concordamos com Marcelo (2009) que as crenças são proposições ou premissas que expressam o que as pessoas consideram verdadeiro. $\mathrm{Na}$ análise das entrevistas identificamos três categorias que consideramos gerais, visto que não distinguem a atividade docente do professor de EP em relação aos demais níveis, etapas ou modalidades de ensino: habilidades relacionadas à forma como o professor organiza e gere o ensino - que chamamos de conhecimentos pedagógicos - e as características pessoais e domínio dos conhecimentos técnicos e práticos da área de atuação — conhecimento disciplinar.

As habilidades relacionadas à forma de organizar e gerir o ensino foram apontadas por seis entrevistados como distintivas do professor. Assim, aspectos ligados ao estabelecimento de interações adequadas ao ensino, seleção de estratégias de aprendizagem produtivas e capacidade de comunicação foram recorrentes nos discursos. São aspectos relacionados ao que Shulman (1986) considera saberes pedagógicos gerais, que se referem àqueles conhecimentos relacionados ao currículo, 
planejamento do ensino, organização de tempo e espaço, gestão de classe, estratégias didáticas e avaliação.

Dois entrevistados destacam, como diferencial do professor referencial, a capacidade de manter a atenção dos alunos, propiciando um clima harmonioso que favoreça a aprendizagem, como elucida o depoimento da prof. ${ }^{a}$ Raquel:

Um bom professor é aquele que consegue ter um domínio da turma sem ser agressivo, que consiga se comunicar e de acordo com as perguntas que ele faça, os alunos consigam responder por que estão entendendo o que ele está falando. A visão de professor bom que tenho é essa: que não precise obrigar a atenção. $\mathbf{A}$ atenção flui. Que ele consegue administrar em diferentes situações e consiga atrair a atenção dos alunos. (Prof. ${ }^{a}$ Raquel).

Aspectos como o manejo da sala de aula e a habilidade de comunicação são diferenciais que ajudam o professor a manter a atenção do grupo na sala de aula, que é o espaço das interações por excelência e, nesse sentido, as respostas confirmam Tardif e Lessard (2007, p. 235), que afirmam:

A interatividade caracteriza o principal objeto de trabalho do professor, pois o essencial de sua atividade profissional consiste em entrar numa classe e deslanchar um programa de interações com os alunos. Isso significa que a docência se desenrola concretamente dentro das interações: estas não são apenas alguma coisa que o professor faz, mas constituem, por assim dizer, o espaço - no sentido do espaço marinho ou aéreo - no qual ele penetra para trabalhar. Por isso [...] ensinar é um trabalho interativo.

A habilidade de mediar o processo de construção do conhecimento, selecionando e utilizando estratégias de ensino adequadas ao conteúdo e aos alunos, também foi apontada como característica distintiva por quatro entrevistados:

Eu acho que um bom professor é aquele que consegue... eu quero ser uma boa professora um dia... aquele que consegue juntar teoria, prática e relacionar com a realidade, o que consegue mostrar a inovação, o que está acontecendo, a evolução das coisas, e tudo isso relacionado com a realidade, com o seu uso efetivo das coisas, o uso do conhecimento, que aí facilita para o aluno entender também... O professor consegue relacionar a teoria com a pesquisa, com a extensão, com a realidade do aluno, eu acho que aquele professor é o melhor. Mas para adquirir essas habilidades ah, não é nada fácil. [...] (Prof. ${ }^{a}$ Vânia). 
Vários depoimentos remetem à relação entre o domínio do conhecimento e a habilidade de organizá-lo de forma adequada para ensiná-lo, o que Shulman (2005, p. 11) identificou como conhecimento pedagógico do conteúdo:

[...] el conocimiento didáctico del contenido adquiere particular interés porque identifica los cuerpos de conocimientos distintivos para la enseñanza. Representa la mezcla entre materia y didáctica por la que se llega a una comprensión de cómo determinados temas y problemas se organizan, se representan y se adaptan a los diversos intereses y capacidades de los alumnos, y se exponen para su enseñanza.

Um desafio apontado pelos entrevistados em relação à organização e gestão da aula diz respeito a inserção das tecnologias digitais que modificaram os ambientes de ensino. Os nativos digitais têm familiaridade com as tecnologias que lhes permitem acesso a múltiplas fontes de informações que se materializam nos hipertextos e meios de comunicação sincrônica, há poucos anos inimagináveis, e que desenvolvem habilidades de processamento flexível. Delaunay (2008, p. 268) ajuda a compreender essa realidade:

Para jovens que, desde que nascem, já conhecem a televisão, os videogames, os computadores, a Internet e os telefones celulares, não existem as "novas" e as "velhas" tecnologias: existem instrumentos para informar e comunicar, jogar ou ajudar nos trabalhos escolares. Essa é uma distinção de adultos - pais, avós, educadores - para os quais, a cada surgimento de nova tecnologia, se faz necessário adquirir novos conhecimentos e novas formas de usos sociais.

Vieira e Vieira (2013) afirmam que os nativos digitais tem melhores condições de uso das tecnologias porque estão mais habituados com elas e, diferentemente das gerações anteriores, deles não se exige readaptação e acomodação de novas informações. Isso reflete na sala de aula, tendo sido apontado como um desafio por quatro entrevistados, dentre os quais transcrevemos o relato da prof. ${ }^{a}$ Carmem:

Então tu vê que o conhecimento teórico eles procuram na internet, nos livros. Então você... É um desafio agora conseguir trazer conhecimento novo para eles, querem uma coisa mais prática, é preciso sair do falar lá na frente e eles copiarem e "sim, senhor", "sim, senhora". Está sendo bem desafiante para mim este ano corresponder às expectativas deles. [...]. Eles esperam mais, t mais conhecimento, querem novidade em sala de aula, querem um diferencial. Então, como eu não tinha experiência antes, a gente foi construindo. Eu tenho que mudar, então, vamos fazendo, pois uma hora vai dar certo. Então agora já vou pegando o jeito de cada um (Prof. ${ }^{a}$ Carmem). 
Dois aspectos transparecem nos relatos dos entrevistados: a constatação das mudanças na conduta dos alunos, ocasionadas pelo acesso às tecnologias, e a necessidade imperiosa de o professor mudar a sua prática pedagógica para adequarse ao novo perfil de aluno, embora ainda não tenha construído referenciais que lhe permitam agir de forma adequada, o que confirma Nóvoa (2019, p. 3): “A escola parece perdida, inadaptada às circunstâncias do tempo presente, como se ainda não tivesse conseguido entrar no século XXI”. O autor ainda afirma:

É impossível ignorar o impacto da revolução digital, bem como a necessidade de diferenciar os percursos dos alunos, mas isso não implica que a escola abdique de ser um lugar de construção do comum. Hoje em dia, a fragmentação a que estamos a assistir no cibermundo, coloca a escola perante a urgência de valorizar a nossa pertença a uma mesma humanidade e a um mesmo planeta (NÓVOA, 2019, p. 4-5).

A questão central para os docentes é como educar gerações que, tendo acesso a um grande volume de informações pela mídia, têm dificuldade de selecioná-las, interpretá-las e transformá-las em conhecimento. Desenvolver habilidades para lidar com as informações de modo interpretativo é função da escola, pois, segundo Goergen (2009, p. 10), “[...] a conquista da autonomia do sujeito e a construção de sua capacidade reflexiva e crítica representa a tarefa central de qualquer educação que se proponha formar cidadãos capazes, não só de atender às exigências do sistema, mas de atuar para a sua transformação e superação”. Entretanto, não é um saber facilmente construído, já que não se trata apenas de domínio da tecnologia, mas requer a elaboração de um novo modelo de ensino-aprendizagem para muitos professores.

Essa diferenciação tende a se agravar se considerarmos o impacto provocado na educação em função do isolamento social imposto pela pandemia de Covid-19, como refletem Morgado, Souza e Pacheco (2020, p. 2)

Mais do que nunca a educação está a passar por um momento de grandes desafios. Nos últimos meses a comunidade educativa tem sofrido imensas alterações nas suas práticas, agudizadas pela ausência física e pela presença invisível a que o mundo da digitalização nos foi habituando. Estamos perante uma situação que requer grande capacidade de elaboração, partilha e inovação entre os atores da comunidade educativa. 
Em relação à segunda categoria, como a docência é autobiográfica, cinco entrevistados apontaram características pessoais que distinguem o professor referencial:

Acho que uma característica fundamental do bom professor é saber ouvir porque muitos professores entram em sala de aula, passam conteúdo e sequer escutam o aluno. Não dão abertura para o aluno falar aquilo que entendeu ou discordar ou questionar. Então acho que o essencial é saber ouvir, é saber dar espaço para o aluno se manifestar, questionar ou tentar mostrar uma visão diferenciada para demonstrar aquilo que ele compreenda o conteúdo e não só o professor ser o dono da verdade (Prof. ${ }^{\text {C }}$ Carmem).

De modo geral, os professores consideram relevante para a docência a habilidade de manter com os alunos relações harmoniosas e produtivas, aspectos ligados à forma como se relacionam com eles e que fazem diferença na sala de aula, como ressalta Franco (2009, p. 15),

Entre o fazer e o saber há a esfera do sentido e do sentir. A direção de sentido, os sentimentos que permeiam a situação da prática conferem diferentes perspectivas ao fazer. Conforme lembra Fusari: sentimentos positivos e negativos estabelecem mediações múltiplas entre o saber e o fazer. Toda ação pedagógica é permeada pela esfera dos sentimentos, do aspecto emocional que sustenta as produções cognitivas.

Entretanto, as relações interpessoais com os alunos se constituem num desafio para os professores que exige um aprendizado permanente de construção de saberes. Por isso, esse foi um aspecto bastante lembrado pelos entrevistados: a necessidade de aprender a lidar com as singularidades da juventude, caracterizada por um certo "choque de gerações":

Eu acho que uma dificuldade é o perfil do educando hoje. Fala-se muito nisso hoje na sociedade pós-moderna, a sociedade líquida, não se tem certeza de nada, mudase muito fácil. As informações transitam de uma forma muita rápida e pouco consistente. Eu não tenho ideia do que é que o jovem quer para si, para a sua vida, para a sociedade. A gente não tem essa compreensão, então fica um pouco mais difícil unir, desafiador, não dá tempo de se preparar para uma aula, assim, com pessoas tão instáveis. Não é culpa deles, é da geração. Nós que somos mais velhos deixamos que aconteça essa bagunça, mas que o nosso papel enquanto parte do que está tendo, está pelo menos "dá um norte, dá uma luz". Acho que esse é um desafio grande (Prof. Valdir). 
Estamos diante de um novo perfil de jovens que são estimulados pelas informações, capazes de realizar simultaneamente múltiplas tarefas e com disposição permanente para interagir com o conteúdo apresentado nas aulas. Além disso, o contexto social em que vivem é diferenciado em relação às gerações precedentes, pois novas formas de agrupamentos e de relações familiares surgiram, ocasionando mudança dos valores socialmente referendados. Essas características exigem do professor outras habilidades: saber dialogar com os alunos, estimular o interesse pela aprendizagem, intervir no desenvolvimento afetivo e moral, dar a atenção à diversidade que os caracteriza, dentre outros saberes.

Tardif (2005, p. 141) menciona essa marca distintiva do trabalho docente:

O trabalho docente exige constantemente um investimento profundo tanto do ponto de vista afetivo como cognitivo [...] essas relações exigem que os professores se envolvam pessoalmente nas interações. [...] nesse sentido a personalidade do professor é um componente essencial de seu trabalho [...] um professor não pode simplesmente "fazer o seu trabalho", ele deve também empenhar e investir nesse trabalho o que ele mesmo é como pessoa.

Um aspecto que chama a atenção nas respostas é que esse "choque de gerações" independe da faixa etária do professor, pois foi mencionado tanto pelos que têm mais idade quanto pelos jovens professores, o que traduz a velocidade das mudanças que caracterizam a sociedade.

Por fim, a terceira categoria apontada por dois entrevistados como requisito para a atuação do professor foi o domínio dos conhecimentos técnicos e práticos da área de atuação, o que inclui os conteúdos da disciplina e a visão ampla do campo de atuação profissional:

O bom professor do ensino técnico deve conhecer bem a sua área. Se não conhece tem de tentar mergulhar nela. Então se vou dar aula de gestão rural, por exemplo, preciso mergulhar na área, contextualizar, usar exemplos diretamente ligados à propriedade rural; o que eles precisarão saber dentro de uma propriedade rural. [...] penso que o segredo está aí. [...] Acho que essencial é tentar se apropriar do maior número de conhecimento da área específica que está atuando e exemplificando, contextualizando; é a forma. [...] (Prof. Jonas).

O domínio do conhecimento da área de atuação é considerado, pelos entrevistados, requisito essencial para o professor e os relatos ratificam Shulman 
(2005), que inclui o domínio do conteúdo da disciplina como essencial porque propicia conhecer os princípios conceituais e suas estruturas, destacando os aspectos centrais do conteúdo ensinado e as habilidades e disposições que os alunos devem desenvolver a partir do ensino, aspecto também apontado por Buchmann (apud Marcelo, 2009, p. 18) que afirma que “conhecer algo nos permite ensiná-lo; e conhecer um conteúdo com profundidade significa estar mentalmente organizado e bem preparado para ensiná-lo de uma forma geral".

Assim, à guisa de conclusão podemos perceber, nas respostas dos entrevistados, saberes que são requeridos na atividade docente dos professores de modo geral, sem particularidades em relação aos cursos da EP, que emergiram nos depoimentos que analisamos na próxima seção.

\section{Singularidades da docência na educação profissional}

As instituições que ofertam a EP, além das características que constituem qualquer escola, tem suas particularidades como a diversidade na oferta dos cursos devido ao tipos de instituições; diversidade de áreas em função dos eixos tecnológicos; diversificação dos tipos de cursos ofertados e perfil da clientela que os frequentam. No caso dos Institutos Federais de Educação, Ciência e Tecnologia (IFEs), essa diversidade ainda é mais acentuada, dada a sua estrutura pluricurricular e multicampi.

Devido a essas características que distinguem a EP das demais etapas/modalidades da educação, indagamos os entrevistados sobre as especificidades da docência na EP e esses destacaram três aspectos que têm implicações no ensino: a diversidade de cursos e perfil dos alunos, as exigências da formação profissional e as finalidades das disciplinas nos cursos.

Quanto ao primeiro aspecto - a diversidade de cursos e perfil dos alunos - , coerente com o princípio da verticalização que orienta as políticas públicas da EP, a instituição pesquisada oferece cursos em diversos níveis e formas de oferta. Assim, o perfil dos alunos em cada uma delas varia bastante, pois os cursos técnicos integrados são diurnos e atendem alunos adolescentes, porém os de PROEJA são noturnos e dele participam alunos adultos; o curso técnico subsequente é diurno e a 
maioria é concluinte do ensino médio e busca profissionalização, o concomitante é constituído por adolescentes que frequentam o ensino médio em outra instituição no turno inverso, enquanto os cursos superiores são diurnos e noturnos e com perfil diferenciado dependendo da origem dos alunos: se já frequentaram ou não curso técnico na área e na instituição.

Dentre os dez entrevistados, seis reportaram essa diversidade como principal característica distintiva da docência na EP, conforme exemplificado no depoimento:

Eu dou aula no técnico em comércio, para o agronegócio, na agronomia, no ADS e vou dar aula à noite no PROEJA e isso implica bastante porque a aula não é a mesma. O princípio é o mesmo, mas cada... cada turma tem um jeito diferente e acaba mudando as minhas aulas. [...] Então tem turmas que o debate vai muito além do que eu tinha programado. Tem turmas que ficam ali, não saem muito, não vão além. E varia também se a turma é do técnico ou da graduação, pois a graduação se torna mais avançada, tem mais os conhecimentos deles. A maturidade, no técnico em comércio do PROEJA faz uma grande diferença, eles acabam tendo mais visão. [...] Na concomitância são mais novos e aprendem mais, assimilam aquele conhecimento mais fácil. E no PROEJA a grande parte deles consegue ir além, visualizar, porque conseguem se ver no emprego e ver os problemas, ou as situações dentro da empresa, conseguem então entender melhor. No PROEJA acho que o maior problema é que não ficam muito tempo, não aguentam muito tempo em sala de aula, chegam tarde ou querem ir embora cedo porque trabalham e estão cansados. E a concomitância já tem aquele ritmo de ensino médio, que tem que cumprir horário, todo regradinho. Então eles ficam e não vão te questionar (Prof. ${ }^{\text {a }}$ Carmem).

Nos depoimentos dos seis entrevistados está expressa a diversidade de perfil de cursos e turmas que, provavelmente, em nenhum outro tipo de instituição seja tão acentuada, pois as escolas de ensino médio e superior têm menor variação do alunado em termos de faixa etária, interesses e exigências profissionais. E que implicações essa diversidade tem para a docência? A dificuldade de domínio metodológico adequado para cada um desses perfis do alunado foi apontada por três pesquisados, conforme ilustra o seguinte depoimento:

Acho que o professor do ensino médio precisa compreender a juventude. 0 adolescente é outra realidade. $O$ ensino médio integrado é uma forma de se trabalhar, com o subsequente é outra forma, é outro perfil. Como trabalhar com jovens? Eu acho que esse é o desafio maior. [...] acho que o desafio maior no nível médio é compreender a juventude. Como trabalhar com as inquietudes, despertar essa área de interesse? Então acho que essa é a grande diferença. Para 
quem é do bacharelado, como nós [...] no superior pega uma gurizada que você já vai tentar, disciplinar, adestrar eles com o que é uma área mais dura, para que ele saia com a mentalidade, que pensem como um agrônomo ou veterinários. Já no técnico vão ser técnicos de nível médio, de grau intermediário, o grau de profundidade não pode ser o mesmo. Até onde vai aprofundar o conteúdo? Quanto você vai atrair a disciplina para eles? Então, isso dá um nó para quem é professor aqui, porque você sai dando aula para o técnico, no outro dia para o superior e tem que reprogramar o teu jeito de dar aula. Então são coisas distintas (Prof. Valdir).

Os três depoimentos ratificam a exigência de domínio didático diferenciado para cada nível, etapa e formas de oferta dos cursos, tarefa que exige bastante esforço do professor porque não há um parâmetro e ele se vê na contingência de preparar e conduzir aulas de forma diferenciada ao longo de um único dia. Embora muitos ministrem o mesmo conteúdo, o conhecimento pedagógico do conteúdo (SHULMAN, 2005) é determinante para que a aprendizagem se efetive.

O segundo aspecto distintivo da docência na EP diz respeito às exigências da formação profissional nos cursos técnicos e superiores, que inclui o domínio da técnica, para a qual a prática desempenha papel relevante e exige perfil diferenciado de professor, aspecto mencionado por quatro entrevistados, conforme evidencia o depoimento a seguir:

Professor da educação profissional tem que ser um professor com certa experiência técnica. Técnica, eu digo assim, em prática. O que é que temos hoje aqui, que é uma grande crítica? Os professores têm uma formação de semideus, entre aspas aqui, são especialistas, bem formados, de universidades conceituadas, muitos com pós-doutorado, mas não têm vivência prática. E na educação profissional é necessário isso. [...] E a gente vê professores que tinham esse conhecimento mais prático do dia a dia conseguiram contribuir melhor ainda. [...] Tem que ter prática. Não tem? (Prof. Clóvis).

Para os pesquisados a experiência prática da profissão de origem é requisito da EP porque viabiliza a exemplificação de situações relativas aos processos de trabalho do campo de atuação que contribuem para facilitar a aprendizagem. Assim, a posição dos entrevistados se coaduna à de Kuenzer (2010, p. 508) que defende que o professor de EP deve ter tido experiência prática do trabalho que vai ensinar porque essa vivência facilita a transposição didática dos conhecimentos científicos: 
[...] não basta a formação teórica, pois ao professor é necessário que domine, para ensinar, como o conhecimento científico fundamenta a prática laboral, conferindo significado e materialidade aos conceitos. Na formação, este movimento se dá do raciocínio científico para a prática, via transposição didática, que deverá incluir atividades que insiram o estudante na realidade do trabalho: laboratórios, casos, visitas, estágios, pesquisas de campo.

Em que pese o fato de cursos dessa natureza demandarem articulação com as técnicas profissionais, os pesquisados em alguns momentos fazem referências à adequação dos cursos às exigências da formação para o mercado, aspecto que caracteriza a EP e que pode ser decorrente da trajetória de sua constituição, que moldou a formação do trabalhador às exigências do mercado e está expressa nas legislações e propostas pedagógicas que nortearam essa modalidade de ensino. Assim, a questão central não é formação para o trabalho, mas a preparação para o mercado, o que contraria a ideia da educação tecnológica.

O terceiro aspecto, apontado por três pesquisados como especificidades da atuação na docência na EP, é a diferenciação de finalidades ou de status entre as disciplinas constituintes da matriz curricular dos cursos técnicos:

Acho que tem diferença entre as disciplinas técnicas e comuns (como física, química, matemática) porque os alunos tradicionalmente estão preparados para terem essas porque já têm desde o ensino fundamental, estão acostumados com elas. Quando a gente chega com uma matéria específica, como é legislação, não conseguem compreender muito. Eles têm uma visão geral do que está acontecendo no Brasil, sabem que isso está ligado ao direito, mas não sabem a importância daquilo e para que serve. Às vezes dizem: "por que é que tem no curso técnico essa disciplina, se a minha formação é em agropecuária?". Então, é bem complexo, é bem difícil, e muitos não têm interesse porque acham que isso não é importante (Prof. ${ }^{a}$ Carmem).

O desenho curricular dos cursos técnicos, especialmente os integrados, abrange componentes curriculares da educação geral, que contém os fundamentos necessários para a formação cidadã e para o prosseguimento dos estudos, e as disciplinas específicas, que devem propiciar a compreensão dos fundamentos científico-tecnológicos dos processos produtivos. Assim, a importância atribuída a cada componente curricular, pelos alunos, depende de suas pretensões ao concluir o curso: há os que ingressam na instituição devido ao seu reconhecimento pela formação geral que propicia, já que dispõe de professores qualificados em todas as 
áreas da educação básica. Para esse grupo, a intenção é o prosseguimento dos estudos e por isso valorizam os componentes curriculares da área geral, que acreditam lhes facilitar o ingresso nas melhores universidades. Em contrapartida, há outro grupo que busca a instituição devido ao seu histórico de formação profissional e pretende seguir a carreira como técnico de nível médio ou ingressar em cursos superiores da mesma área. Esses valorizam mais os componentes curriculares da área específica.

Assim, nesta seção abordamos os conhecimentos que caracterizam a docência na EP que, pela sua forma de organização e estrutura institucional impõem outros desafios aos seus professores, que a singularizam em relação aos demais docentes.

\section{Considerações finais}

Ao definirmos o percurso investigativo do estudo, o objetivo deste trabalho foi analisar como os professores que atuam na educação profissional exercem a docência, enfocando os conhecimentos e saberes requeridos aos profissionais em exercício em qualquer nível ou modalidade de ensino e o que os particulariza, ou seja, que aspectos da docência são singulares à educação profissional. Assim, na sequência apontamos, em linhas gerais, breves conclusões sobre os aspectos analisados.

Os dados da pesquisa indicam que o exercício da docência requer a construção de saberes que denominamos "universais" porque se aplicam a qualquer relação pedagógica escolar, enquanto há conhecimentos ou habilidades que singularizam a docência na EP.

Em relação aos conhecimentos universais destacam-se os pedagógicos - e especialmente o conhecimento pedagógico do conteúdo (SHULMAN, 2005) —, as características pessoais dos docentes e o domínio do conteúdo disciplinar, saberes já amplamente debatidos nos trabalhos de autores referenciais como Tardif e Shulman, dentre outros. Nesse sentido são particularmente desafiadoras as singularidades da juventude, que se distancia rapidamente de seus professores, e especialmente o uso das novas tecnologias de informação e comunicação.

Em relação às particularidades da docência na EP, a conclusão é de que ela se diferencia pois requer a construção de processos e técnicas operativas que exigem o domínio de estratégias de ensino distintas das práticas tradicionais e acadêmicas. 
Quanto aos saberes requeridos dos professores da EP, as particularidades que os desafiam estão relacionadas à diversidade de cursos e perfil dos alunos, às exigências da formação profissional e às finalidades das disciplinas nos cursos. Para os pesquisados é importante que a atuação nessa modalidade de ensino esteja calcada no domínio dos conhecimentos técnicos e da prática profissional na área.

$\mathrm{Na}$ EP, devido ao princípio da verticalização do ensino, os professores dos IFES atuam em cursos diferenciados, desde o ensino médio ao stricto sensu, com alunos de diferentes idades, etapas de escolaridade, nível socioeconômico, características étnico-culturais, dentre outras particularidades que lhes exigem construir saberes pedagógicos para lidar com essa diversidade. Também requer do professor e do aluno o domínio de conhecimentos processuais ou procedimentais que se referem às habilidades ou destrezas demonstradas por meio da ação de um saber-fazer e que se manifestam quando se responde ao "como se faz uma coisa" e, em geral, se pode demonstrar, fazendo-a.

Por fim, convém registrar que este trabalho não teve a pretensão de apontar verdades ou conclusões definitivas, à medida que a análise proposta pode ser apenas uma das leituras possíveis dos dados que produzimos no lócus pesquisado. Outras possibilidades de interpretação, reflexão e análises ficam em aberto para fomentar o diálogo e contribuir para a construção de conhecimentos sobre a docência na educação profissional. De nossa parte, lembramos Freire (2000, p. 32), que afirma: "Pesquiso para constatar, constatando, intervenho, intervindo educo e me educo. Pesquiso para conhecer o que ainda não conheço e comunicar ou anunciar a novidade".

\section{Referências}

BRASIL. Lei no 13.005, de 25 de junho de 2014. Aprova o Plano Nacional de Educação (PNE) e dá outras providências. Disponível em: http://www.planalto.gov.br/ccivil_03/_ato20112014/2014/lei/113005.htm. Acesso em: 16 jun.2021.

BRASIL. Lei $\mathrm{n}^{\circ}$ 13.415/2017, de 13 de fevereiro de 2017. Altera as Leis $\mathrm{n}^{\circ}$ 9.394, de 20 de dezembro de 1996, que estabelece as Diretrizes e Bases da Educação Nacional, e no 11.494, de 20 de junho 2007, que regulamenta o Fundo de Manutenção e Desenvolvimento da Educação Básica e de Valorização dos Profissionais da Educação, a Consolidação das Leis do Trabalho - CLT, aprovada pelo Decreto-Lei no 5.452, de $1^{\circ}$ de maio de 1943, e o Decreto-Lei ${ }^{\circ}$ 236, de 28 de fevereiro de 1967; revoga a Lei $\mathrm{n}^{\circ}$ 11.161, de 5 de agosto de 
2005; e institui a Política de Fomento à Implementação de Escolas de Ensino Médio em Tempo Integral. 2017. Disponível em: http://www.planalto.gov.br/ccivil_03/_ato20152018/2017/lei/L13415.htm. Acesso em: 10 jun. 2021.

BRASIL. Instituto Nacional de Estudos e Pesquisas Educacionais Anísio Teixeira (Inep). Relatório do $3^{\circ}$ ciclo de monitoramento das metas do Plano Nacional de Educação - 2020. Brasília: Instituto Nacional de Estudos e Pesquisas Educacionais Anísio Teixeira, 2020a.

BRASIL. Ministério da Educação e Cultura; Instituto Nacional de Estudos e Pesquisas Educacionais Anísio Teixeira (Inep). Sinopse Estatística da Educação Básica 2020. Brasília: MEC/INEP, 2020b. Disponível em: https://www.gov.br/inep/pt-br/acesso-ainformacao/dados-abertos/sinopses-estatisticas/educacao-basica. Acesso em: 16 jun. 2021.

BRASIL. Ministério da Educação. Resolução CNE/CP no 1, de 5 de janeiro de 2021. Define Diretrizes Curriculares Nacionais Gerais para a Educação Profissional e Tecnológica. Disponível em: https://www.in.gov.br/web/dou/-/resolucao-cne/cp-n-1-de-5-de-janeirode-2021-297767578. Acesso em: 20 jun.2021.

DELAUNAY, G. J. Novas tecnologias, novas competências. Educar, Curitiba, n. 31, p. 276284, 2008.

FRANCO, M. A. S. Prática docente universitária e a construção coletiva de conhecimentos: possibilidades de transformação no processo ensino-aprendizagem. Cadernos de pedagogia universitária, São Paulo, n. 10, 2009.

FREIRE, P. Pedagogia da indignação: cartas pedagógicas e outros escritos. São Paulo: UNESP, 2000.

MARCELO, C. G. A identidade docente: constantes e desafios. Revista Brasileira de Pesquisa sobre Formação Docente, Belo Horizonte, v. 1, n. 1, p. 109-131, 2009. Disponível em: http://formacaodocente.autenticaeditora.com.br. Acesso em: 19 out. 2020.

GOERGEN, P. L. Sociedades complexas e formação de professores. Passo Fundo, 2009. (Palestra proferida no Colóquio Sociedades Complexas e Formação de Professores).

IMBERNÓN, F. La profesión docente ante los desafíos del presente y del futuro. In: MARCELO, G. (Org.). La función docente. Madrid: Síntesis, 2001. p. 27-41.

KANAN, L. A; ARRUDA, M. P. A organização do trabalho na era digital. Estudos de Psicologia, Campinas, v. 30, n. 4, p. 583-591, out/dez. 2013. Disponível em: https://www.scielo.br/j/estpsi/a/RJcLVpKBksMkFjHxSVCM8Mh/?lang=pt. Acesso em: 25 jun. 2021.

KUENZER, A. Z. Formação de professores para a educação profissional e tecnológica. In: DALBEN, A. L.; DINIZ, J.; LEAL, L.; SANTOS, L. (Org.). Coleção Didática e Prática de Ensino. Belo Horizonte: Autêntica, 2010. p. 497-518. Disponível em: http://www.academia.edu/4894113/Colecao_didatica_e_pratica_de_ensino_-

_Livro_3_PDF. Acesso em: 10 jun. 2014

ÓVOA, A.A. Os professores e a sua formação num tempo de metamorfose da escola. Educacão \& Realidade, Porto Alegre, v. 44, n. 3, 2019. 
MORGADO, J. C.; SOUSA, J.; PACHECO, J. A. Transformações educativas em tempos de pandemia: do confinamento social ao isolamento curricular. Práxis Educativa, Ponta Grossa, v. 15, e2016197, p. 1-10, 2020. Disponível em: https://revistas2.uepg.br/index.php/praxiseducativa/article/view/16197. Acesso em: 28 jun. 2021.

OLIVEIRA, M. R. N. S; NOGUEIRA, C. G. A formação de professores para a educação profissional e o Plano Nacional de Educação (PNE): quais as perspectivas? Revista Holos, Natal, v. 6, n. 32, p. 145-155, 2016. Disponível em: http://www2.ifrn.edu.br/ojs/index.php/HOLOS/article/view/4987. Acesso em: 22 maio 2021.

SHULMAN, L. S. Those Who Understand: Knowledge Growth in Teaching. Educational Researcher, v. 15, n. 2, p. 4-14, fev. 1986.

SHULMAN, L. S. Conocimiento y enseñanza: fundamentos de la nueva reforma. Profesorado. Revista de Currículum y Formación de Profesorado, Granada, v. 9, n. 2, p. 1-30, 2005.

TARDIF, M. Saberes docentes e formação profissional. 7. ed. Petrópolis: Vozes, 2005.

TARDIF, M.; LESSARD, C. O trabalho docente: elementos para uma teoria da docência como profissão de interações humanas. Petrópolis: Vozes, 2007.

VIEIRA, M. M. M.; VIEIRA, J. A.; ARAÚJO, M. C. P. A formação dos professores da educação profissional como objeto de estudo dos Programas de Pós-Graduação no Brasil: análise das produções acadêmicas. Revista Educação em Questão, Natal, v. 56, n. 49, p. 139-167, jul./set. 2018. Disponível em: https://periodicos.ufrn.br/educacaoemquestao/article/view/14320. Acesso em: 22 jun. 2021.

VIEIRA, M. M. M.; VIEIRA, J. A. Educação e formação humana na sociedade digital. Reflexão e Ação, Santa Cruz do Sul, v. 21, n. 2, p. 115-133, jul./dez. 2013.

RECEBIDO: $19 / 07 / 2021$

APROVADO: $21 / 09 / 2021$

RECEIVED: 07/19/2021

APPROVED: 09/21/2021

RECIBIDO: $19 / 07 / 2021$

APROBADO: 21/09/2021 